Pp. $336-362$

DOI: http://dx.doi.org/10.24093/awejtls/vol5no1.23

\title{
The Integration of Computer-Aided Translation Tools in Translator-Training Programs in Saudi Universities: Toward a More Visible State
}

\author{
Lama A. Al-Rumaih \\ Translation Department, College of Languages \\ Princess Nourah Bint Abdulrahman University \\ Riyadh, Saudi Arabia
}

Received:1/4/2021

Accepted: $1 / 21 / 2021$

Published: 2/24/2021

\begin{abstract}
The paper aims to investigate the current state of Computer-Aided Translation (CAT) tools integration into the translator-training programs of some universities in Saudi Arabia, which are King Saud University (KSU), Princess Nourah University (PNU), Imam Mohammed Ibin Saud Islamic University (IMSIU), Prince Sultan University (PSU), and Saudi Electronic University (SEU). The investigation touched upon the sufficiency of this integration and the usability of these tools by the translation students and graduates of these universities in different translation courses and tasks, which contributes to enriching the field of translation technology, due to the scarcity of such studies in the investigated region. The study used a mixed-methods approach to enhance the validity of the data. The results showed that CAT tools have not been integrated effectively yet into the translator-training programs of the universities under study, as not all of them provide CAT courses. While the universities that do, lack some elements which can help to promote the integration of these tools into the programs. As for the usage of these tools, the findings revealed that a significant percentage of the participants do not use CAT tools in their translation tasks, and more than half of them do not use CAT tools in other translation courses. These findings suggest more integration of CAT tools in the universities' translator-training programs to enhance their outcomes and increase their graduates' opportunities in the job market.

Keywords: Computer-Aided Translation tools, job market, Saudi universities, technology, translation, translator-training programs

Cite as: Al-Rumaih, L. A. (2021). The Integration of Computer-Aided Translation Tools in Translator-Training Programs in Saudi Universities: Toward a More Visible State. Arab World English Journal for Translation \& Literary Studies 5 (1) 336362.

DOI: http://dx.doi.org/10.24093/awejtls/vol5no1.23
\end{abstract}


AWEJ for Translation \& Literary Studies Volume, 5 Number 1. February 2021

The Integration of Computer-Aided Translation Tools

Al-Rumaih

\section{Introduction}

Modern technology makes revolutionary changes in the world, and it becomes an inseparable part of people's life. Almost all aspects of society are going through a series of continuous changes because of technology, and its effect has inevitably reached translation as part of society. With the expansion of technology, new inventions took place in the translation industry. Among these inventions were Computer-Aided Translation tools (CAT). These tools made a massive shift in the translation industry, and they have been discussed from different perspectives in the literature (Al-Jarf, 2017; Alotaibi, 2014; Bowker, 2002, 2015, 2019, 2020; Sin-wai, 2010, 2013, 2015), among others. Some of these studies explicitly indicate the need for more technology and CAT tools integration into the translator- training programs.

Sin-wai (2010) argued that the academic institutions are "possibly the best places to acquire the knowledge and skills of computer-aided translation" (p.85) because of the opportunity that they offer to combine in-depth study with the practical experience from internships or "projects in a real-life setting" (p.86). Meanwhile, many universities worldwide, including some Saudi universities, integrated CAT tools into their translator- training programs. However, some evidence aroused the question about the sufficiency of this integration. For example, Samson (2005) mentioned that many companies in the translation industry constantly complain about the translators' efficiency, including new graduates in using CAT tools. while Alotaibi (2014) stated that the participants in her study have never been acquainted with CAT tools, and they were advised to avoid using technology in translation with the exception of some electronic dictionaries. Moreover, Fatani (2009) indicated that the negligence of the translation industry by the governmental institutions, companies, and organizations in Saudi Arabia is due to the lack of qualified translators at different levels, including the technical level.

What is more, most of the studies conducted on Saudi universities did not mainly investigate the state of CAT tools in the translator-training program of the universities and their usage by the translation students and graduates, but other issues within the same context (e.g., the perception of the tools, the attitude toward the tools, the teaching of the CAT courses), etc. The scarcity of studies on this topic necessitates further investigations. Therefore, the aim of this study is twofold: first, to explore the state of CAT tools integration in some Saudi universities (the CAT tools investigated are the software packages and not the electronic dictionaries or search engines). Second, to investigate the extent to which the students and graduates of these universities use CAT tools in different translation tasks and courses.

The study aspires to contribute to the field of translation, especially translation technology, as it tackles a topic that has not been discussed mainly in the previous studies conducted on Saudi universities. Also, it can be beneficial to raise the awareness of the decision-makers and curriculum developers in the universities of the region to consider the state of CAT tools in their translatortraining programs. Moreover, the study's findings can motivate them to make some changes to the translation curricula of their universities in a way that addresses the market needs more and the technological developments in the translation field. All of which can contribute to enhance the universities' outcome and increase their graduates' opportunities in the job market.

Arab World English Journal for Translation \& Literary Studies 
AWEJ for Translation \& Literary Studies Volume, 5 Number 1. February 2021

The Integration of Computer-Aided Translation Tools

Al-Rumaih

A mixed-methods approach is used in this study as an attempt to answer the following questions:

1. What is the current state of CAT tools integration into the translator-training programs in Saudi universities?

2. To what extent do translation students and graduates of Saudi universities use CAT tools in different translation tasks and courses?

\section{Literature Review}

\section{Computer-Aided Translation Tools}

European Association of Machine Translation (n.d.) has defined CAT tools as "translation software packages which are designed primarily as an aid for the human translator in the production of translations" (para. 3). Whereas, Bowker (2002) described them in a broader sense as "CAT technology can be understood to include any type of computerized tool that translators use to help them do their job" (p. 6). Both definitions indicate that the translation is mostly done by human translators, and the machine is utilized to facilitate the process.

In contrast to the MT goal, CAT aims to achieve a high-quality translation through human translators' interaction with the computers that facilitate the process (Sin-wai, 2015). CAT tools have gained popularity in the translation market and among professional translators, which necessitated the teaching of these tools to the translation students to help them be familiar with such tools and use them in the translation process (Bowker, 2002). Some of the main tools that the students need to be introduced to and practiced are translation memory, terminology management systems, localization tools, and translation management systems, as Bowker (2015) stated that they are what the translators most commonly will encounter and be required to possess in the professional settings. These tools are usually not used separately, but rather with a large set of tools in the translation environment (TEnT) (McBride, 2009).

Since it is difficult to predict the future jobs of the translation students, introducing them to various tools can strengthen their technical skills and help them be more confident in a professional workplace (Bowker, 2015). In 2006, a survey of 874 TM users revealed that most participants use more than one tool, which was on the average of three to four tools (Lagoudaki, 2006). However, introducing the students to different types of tools without clear guidance can be misleading. Thus, part of the process should give priority to embedding the future translators with knowledge about when to use these tools and for what purpose and case (Bowker, 2019). Moreover, they should be introduced to the ethics of using technological tools in translation. This concept has recently come to the fore and soon held an increasingly significant place in the field (Bowker, 2020). The translation students need to be aware of such a concept before they enter the job market. One of the important aspects pertaining to the ethics of translation technologies is the over reliance on these technologies in translation. According to (Bowker, 2020), the translators' over reliance on technological tools when translating can lead to ethical problems, such as jeopardizing the privacy and the confidentiality of the translated data. Therefore, the curriculum developers and course designers need to take these aspects into account to provide the students with well-planned courses to prepare them for the real-life work environment.

Arab World English Journal for Translation \& Literary Studies 
AWEJ for Translation \& Literary Studies Volume, 5 Number 1. February 2021

The Integration of Computer-Aided Translation Tools

Al-Rumaih

\section{Translation Industry in Saudi Arabia}

The translation industry in Saudi Arabia is flourishing year after year. However, there are a few research studies on the translation industry and translation production in Saudi Arabia (Abughararah, 2017). According to the survey conducted by (Harabi, 2009), the role of supply especially the labor force in Saudi Arabia was poor and it consequently affected the contribution of the translation industry in the country. On the other hand, the role of the capital and local demand for translated books was good. Another problem indicated in the survey and had a negative impact on the development of the translation industry was the difficulty of determining the actual number of translators and interpreters, due to the absence of official authority for the translation industry that should be responsible for the translators' registration and translation activities.

On a similar note, Fatani (2009) investigated the state of the translation industry in Saudi Arabia, mainly its state in the Saudi market. The study revealed various experiences; however, a great percentage of the companies surveyed did not have translation departments and they relied on other translation suppliers such as licensed translation offices, and sometimes the translation tasks were done by bilingual employees, due to the lack of qualified translators. Also, some organizations had no translation departments and they did not use technology in translation because they consider it a threat that jeopardizes the position of the human translators. Regarding the official institutions, such as the Chamber of Commerce, which is responsible for listing the licensed translation agencies and offices in the country, she indicated that the information offered by them was not always reliable, as a number of certified translation offices were not on their lists.

The need for an official authority for the translation industry has recently been discussed by some Saudi translators, especially those who hold higher degrees and have long experience in the field. They addressed in social media the need for an official authority and they succeed to some extent to draw the attention of other translators to consider this issue. The discussion and the demands to establish an official authority lasted for a long period of time, then some changes happened. At the beginning of the year 2020, the Ministry of Culture established "The Literature, Publishing, and Translation Commission," among 11 new commissions. Regarding the translation, the commission aims to create opportunities for the Saudi translators, arrange translation activities, shed light on the Saudi literature and culture, and transfer knowledge about other cultures to Saudi Arabia through translation. Additionally, the Minister of Labor and Social Development announced his acceptance for establishing the "Association of Saudi Translators and Interpreters." All of these developments can have a great impact on the future of the translation industry in Saudi Arabia.

In the academic context, Abu-ghararah (2017) asserted a significant gap between the academic training and what the Saudi translation market is looking for in the translators. Also, the Saudi market and many governmental organizations require qualified translation in various specialized fields. She stated that translator-training programs in Saudi Arabia failed to keep pace with the developments in the translation industry, which caused the gap in the first place. The same issue was mentioned by (Fatani, 2007) regarding the lack of reflecting the market needs in the academic training courses. Therefore, the translation programs in Saudi Arabia need to consider the translation market demands and equip their students with a set of required competencies to contribute to the translation industry. Among the competences Abu-ghararah (2017) highlighted was technological competence, which does not only mean knowing how to use the computer but 
also understanding the role of technology in the translation industry to make use of it effectively in the translation process.

In regard to the Saudi market, Fatani (2009) believes that it offers plenty of opportunities for the translators. In other words, for her:

The recent entry of Saudi Arabia into the World Trade Organization, the irreversible globalization of Saudi businesses, the versified and large number of local sectors that have recently entered into strategic partnerships with Microsoft, together with the internet revolution have made translating and interpreting services a rapidly growing area with excellent employment opportunities. (p. 2-3)

These opportunities need to be given to qualified translators with great technical skills to be able to meet the market expectations. To achieve this level of preparing professional translators, the universities' courses need to be designed for this purpose. Elshafei (2014) drew a correlation between the students' translation and the design of the translation courses, she indicated that the "weakness in students' translation can, in turn, affect the quality of their preparation for [the] labor market, resulting from the lack of well-designed courses of translation" (p. 146). Thus, she stated that the process of planning a curriculum should focus on "narrowing the gap between what the labor market needs from the modern translator and the courses offered by training institutions, universities and colleges" (p. 145).

For her part, Fatani (2007) suggested that providing the students with a lot of technology in the form of software applications, technically qualified instructors, and professional IT maintenance teams can improve the translation training programs, as the future of these students revolves around technology, whether as freelancers or employees. Translation technology has offered many new roles related to translation, such as post-editing, project management, quality assessment, etc. While these jobs may seem to be threatening to some translators, others can offer a range of services, and these jobs are not problematic for them.

In this day and age, everything is being digitized, which means that paper copies will be less used, as Krüger (2016) suggested that "the good old days of pen-and-paper translation are inevitably coming to an end" (p. 114). Thus, the translators who do not wish to work with technology and translate using traditional ways will be replaced not by the technology but by the translators who possess excellent knowledge and control of that technology (Pym, 2011). On the other hand, Bowker (2019) advised the translators who find translating with technological tools less satisfying to reject the jobs that require such practice, as they conflict with their interests.

\section{The Integration of CAT Tools in Translation Programs}

The development and expansion of technology made it imperative for the translators to possess some technical skills. Kenny (1999) mentioned that the integration of CAT tools into universities' curricula could widely open the doors for new scopes of research and pedagogy. Many research papers have been conducted on the application of CAT tools and their integration in the curricula of translation programs. In China, for example, research studies on translation technologies seem to be gaining more attention by researchers. Some of these studies discussed 
AWEJ for Translation \& Literary Studies Volume, 5 Number 1. February 2021

The Integration of Computer-Aided Translation Tools

Al-Rumaih

the status of using CAT tools in Chinese universities and how they still need to pay extra attention to the matter.

In this vein, Yao (2017) focused on the present situation of CAT tools adoption in teaching translation in China. To investigate the status of using CAT tools and the problems of adopting them in translation teaching, she conducted a survey, which was distributed to the English translation teachers in different cities in China. The results showed that the primary reason for the lack of integrating CAT tools in teaching translation in Chinese universities was the lack of the teaching staff's familiarity with CAT tools, as a great percentage of them were not very familiar with these tools and did not understand their purpose. Therefore, she suggested some solutions to enhance the situation, such as increasing the awareness of the importance of such tools for the students' future career among translation teachers. Also, providing the staff in charge of teaching CAT courses with more training, as they showed a positive attitude and willingness to take CAT training courses.

On the other hand, studies of attitudes toward these tools can give a glance at the state of integrating them into the translator- training programs. This can be seen in Alotaibi's (2014) study when she explored the degree of knowledge, expectations, and attitudes of 103 female translation students at KSU toward using CAT tools. The study revealed that the students had no prior knowledge of CAT tools, and most of the teaching staff do not use computers in the lectures. Moreover, it mentioned that free online services and tutorials were used regarding commercial applications, such as SDL Trados, due to the lack of the university's fund. In the face of these issues, the researcher found a relationship between the students' knowledge of CAT tools and their attitude toward the discipline. The more familiar they were with CAT tools, their potentials, and limitations, the more positive their attitude was toward them. In addition, the study emphasized integrating technology in general and CAT tools in particular in the translation program and encouraging the students to use these tools across translation courses and not only in CAT courses to enhance their technical skills and increase their productivity.

While professor Al-Jarf (2017) investigated the integration of technology in the translatortraining program of the same university. In the study, she interviewed 72 female graduates from KSU who work as Arabic-English and English- Arabic translators and/or interpreters. The results revealed that the computer courses which the students took were inadequate to prepare them for their future job. Thus, she stressed on the importance of integrating technology into the translation curriculum, as the participants showed their resentment for not practicing such technological tools and software efficiently. In the end, she drew attention on extending the usage of these tools to other translation courses, which was noted by (Alotaibi, 2014) too.

Needless to say that both Alotaibi (2014) and Al-Jarf's (2017) studies are limited to the female section in the university and do not cover the situation in the male section, which may have similar or different findings. In spite of this fact, they highlighted the same issue regarding the need for integrating more technology in the translator-training program of the university.

On a similar note, Mohammed (2020) dealt with the attitude of translation students at two universities in Yemen toward the translation programs offered by their universities. The analysis 
AWEJ for Translation \& Literary Studies Volume, 5 Number 1. February 2021

The Integration of Computer-Aided Translation Tools

Al-Rumaih

was based on the Process of Acquisition of Translation Competence and Evaluation (PACTE) model, which includes six sub-competencies. One of these competencies is the instrumental subcompetence, which concerns the use of technology and CAT tools to enhance the students' skills. The results showed that the programs neither integrate technology nor CAT tools. Also, some translation departments did not even offer a course in the computer for the students. Consequently, the students were not familiarized with the technological tools required in the translation market. As for the translation lectures, the traditional way of translating was more dominant and the labs were not used for practical lectures. Overall, the study revealed that the students had a negative attitude toward the translation programs for which they failed to improve their translation skills.

Meanwhile, Abu Dayyeh (2020) examined the usage of CAT tools in Arabic/ English translation by Palestinian practicing translators and translation trainees from two universities in Palestine. The study investigated several aspects regarding CAT tools, such as the participants' source of familiarity with CAT tools, the extent of their usage of CAT tools in the translation process, their perception of the reliability of these tools, etc. The results showed that a great percentage of the participants who used CAT tools highly suggested them to be used in the translation process, as they are convenient in saving the translators' time. On the other hand, the study showed a lack in the usage of some tools, such as translation memories and terminology management systems by the participants, due to the lack of knowledge and training of such tools alongside the general perception of them as complex and insufficient for the Arabic language. In conclusion, he placed emphasis on the importance of technology for the translators' future careers, and addressed the need for integrating CAT tools into the translation curriculum, as the majority of the participants confirmed the necessity of such integration.

Although all of the above studies explicitly reflected the need for more technology and CAT tools integration into the translator- training programs, some universities and academic institutions are still lagging behind. The ineffective integration of such tools was attributed to many factors, such as the lack of qualified teaching staff, the lack of awareness of the significance of CAT tools for the translation students and graduates in the professional settings, the lack of the universities' fund, as some CAT programs are expensive to be installed and maintained regularly, and so forth (Al-Jarf, 2017; Alotaibi, 2014; Mohammed, 2020; Yao, 2017).

To activate the integration process of CAT tools into the translator-training programs, the curriculum developers should take the CAT courses into account, as they are at the heart of this process. Integrating CAT courses in the translation curricula and teaching the translation students such courses require an enormous amount of effort. There is no particular level in which CAT tools and technologies should be integrated (Bowker \& Marshman, 2009). However, Bowker (2015) supported the integration of technologies at early levels and at a gradual pace, as it can help the students to build a firm technological base. If the teaching staff is not capable of handling the integration appropriately, the students' experience can be negatively affected, which can affect their opportunities in the job market (Yao, 2017). The same attention should be drawn to the translator-training programs in Saudi universities, as the studies of (Al-Jarf, 2017; Alotaibi, 2014) indicated the lack of students' usage of such tools, which requires further updates and considerations of the state of CAT tools integration in the translation program of the investigated university.

Arab World English Journal for Translation \& Literary Studies 342

ISSN: 2550-1542 | www.awej-tls.org 
Moreover, translation instructors need to be aware of the importance of these tools and not just the students. This can be initiated by raising their awareness about the concept of Knowledge Sharing (KS), which was used by Ghabban, Selamat, and Ibrahim (2018) in their study that was conducted on some Saudi universities. The study indicated that practicing KS and using technology in the practice enhanced the scholarly publications in the Saudi universities included in the study, as the communication and sharing knowledge between the academic staff increased. This concept can be introduced to the teaching staff and encourage them to share the knowledge they have about their courses with each other. By practicing KS, the teachers of other courses will be able to perceive the importance of using CAT tools across translation courses and disseminate that to students.

In contrast, restricting the use of these tools to technology courses can result in a gap between theory and practice; consequently, the students' preparations for the professional contexts can be adversely impacted (Bowker \& Marshman, 2009). Pym (2013) advised that technological tools should not only be used in technology core courses but rather across translation courses as much as possible. While Kiraly (2014) touched upon an important aspect related to the CAT courses, which is the number of these courses in the translation program. He stated that providing only a course on technology cannot guarantee the students' acquisition of the technical competence needed in the professional settings. Thus, the students need more exposure to technology and CAT tools to become aware of these tools, their benefits, drawbacks, and eventually become competent in using them.

Returning to the main question of the state and usage of CAT tools, the above studies did not focus primarily on investigating such matters, however, they focused on other aspects and issues within the same context. Some of them, especially those conducted on Saudi universities, were limited to one university or section. The variety of their explicit indications regarding the need for more technology and CAT tools integration necessitated further investigations. Therefore, the current study is an attempt to fill this gap, by providing answers to the present state of CAT tools integration in some Saudi universities, which are the software packages, whether desktopbased or cloud-based, and the extent of their usage by the students and graduates of these universities.

\section{Methods}

The study utilizes a mixed-methods approach (convergent design). The mixed-methods approach is used to make the research problem more understandable (Creswell \& Clark, 2017). While the convergent design is used to validate the study by comparing and contrasting the results of the quantitative and qualitative data in the interpretation (Creswell \& Clark, 2017).

\section{Participants}

The study includes five universities, which are King Saud University (KSU), Princess Nourah University (PNU), Imam Mohammed Ibin Saud Islamic University (IMSIU), Prince Sultan University (PSU), and Saudi Electronic University (SEU). These universities were selected as they, to some extent, represent Saudi universities and meet the study's criteria. All of them provide translation courses, regardless of the program's name, and supply the market with certified translators and interpreters. Another rationale for the choice is their location. All of them are 
located in the same city as the researcher, which facilitated the communication with the universities' officials and the interviewees when needed.

Regarding the participants of the study, the main criteria for selecting them were their major, the university they study/ graduated from, and the year of graduation. Therefore, the sample included male and female English-Arabic translation students/graduates at the universities mentioned above who graduated during (2017-2019) or expected to graduate in the next two years. The study included both genders to be more representative and explore the situation in both sections which most of the previous studies in the literature, especially the ones conducted on Saudi universities, did not focus on as they only investigated one section. The sample was collected from the groups of English/ Arabic translation students in social media platforms, who belong to the universities under study. This method was created by (Alshrief, 2019) to make the data collection procedure from the students' group on social media more structured and systematic.

As for the year of graduation, it is determined to guarantee that the data collected are recent and relevant to the present study. Also, to track the developments of the translation programs in terms of CAT tools integration and its benefits for the students and graduates. Therefore, the participants who graduated at least one year before or after the determined period were also included in the study.

\section{Materials}

Study Plans

They are documents that contain the plan of the entire program and give an overview of each semester and its courses. Some of them attach the course specifications, which are documents that contain detailed information about each course. To explore the current state of CAT tools integration into the translator-training programs, all of the programs' study plans were checked. Some of the course specifications were obtained upon a formal request, and some were available on the universities' websites. Only the courses related to CAT tools were focused on since these courses are of concern to the current study. They are six documents in total, as some of the universities have two study plans. These course specifications were found to be an efficient source to explore the state of CAT tools integration in the translation programs, as their content is detailed impartially. Also, the courses form the program's curriculum, therefore, their course specifications play a central role in developing the students' skills (Elshafei, 2014).

\section{Survey}

According to Saldanha and O’Brien (2014), “questionnaires have been used to some extent in research on translation, most notably to research topics on the translation profession, technologies or to survey translation student opinions about teaching and learning" (p. 151). Hence, the survey was found to be an appropriate tool to explore the students/graduates' usage of CAT tools in different translation tasks and courses. Also, to have a more inclusive view of the state of CAT tools from their perspective. It comprised close-ended questions and it was designed to assess four constructs, which are: the participants' profile, their familiarity with CAT tools, their usage of CAT tools, and the situation of CAT courses in their universities and their opinions about them. Moreover, it was conducted in an electronic form (Google Form). Electronic surveys can reach a great number of people at a speedy pace (Taylor, 2000); consequently, it can help to 
increase their participation as the internet is now available to almost everyone. Regarding the number of participants, 340 participated in the survey, and after excluding the irrelevant responses, the total number of participants was 318 .

\section{Semi-structured Interview}

To assure the validity of the research data, a semi-structured interview was conducted. It was designed to obtain insightful details about the participants' experience with CAT tools and their opinions about the CAT courses in the translation programs of their universities. The total number of interviewees was 34, and the interview took from 15 to 30 minutes each. As interviews involve a higher level of interaction and flexibility (Foddy, 1994), they enable the researcher to get more insights that he/she could not obtain by other procedures. All the interviews were recorded and transcribed with the consent of the participants. Since research ethics are of concern to the author, the participants' anonymity was guaranteed.

\section{Research Procedures}

The data collected from the course specifications and interviews were analyzed using the content analysis method, which includes sorting the relevant responses into codes and assigning themes for them, searching for patterns, and making explanations (interpretations) (Dornyei, 2007). While statistical methods were used to analyze the quantitative data, which were collected from the survey. The analyzed data were triangulated to promote the reliability and validity of the study. The results then were correlated and contrasted with previous studies in the literature to draw conclusions on the state of CAT tools and their usage (see Discussion).

The process started by collecting the course specifications of the translation programs. Then, the materials were sorted, and only CAT-related courses were analyzed. The prerequisite courses, the graduation projects, and the other translation courses were also viewed to investigate whether the CAT tools were integrated into them or not.

After that, the process of conducting the survey began. The first step was determining the target population and the survey form. To draw an appropriate sample of the target population, the groups of the translation students of the five universities were targeted in three social media platforms, which are Twitter, WhatsApp, and Telegram. These groups usually include students and graduates of the same university and major. After determining the groups, their members' information was collected and arranged in schedules using Microsoft Excel. The sample consisted of 1001 accounts and mobile numbers in total. After that, the survey was sent to them. It was distributed on February 1, 2020, and closed on March 15, 2020. Furthermore, the participants who agreed to provide their contact information were scheduled for further semi-structured interviews.

Since the interview is semi-structured, it involved a list of questions prepared in advance by the interviewer (Seliger \& Shohamy, 1989). After interviewing the participants, the recorded interviews were transcribed. Then, the data set was filtered to find reappearing patterns that could emerge from it (Seliger \& Shohamy, 1989) for the purpose of coding. To do so, the data set was reviewed many times by the researcher to be familiar with all of its features. Also, it was confirmed by checking the audio records of each interview while reviewing the data set simultaneously (Magnusson \& Marecek, 2015). 
Next, the entire data set was coded initially and Followed by a second-level coding (Dornyei, 2007). MS Word 2019 was used to carry out the process, and each code was highlighted with a different color to be distinguished later. After assigning the codes, the data set was revised, and overlapped codes were identified (Saldanha \& O'Brien, 2014). Several codes emerged from the data set, which are: disappointment, challenges, limitations, indication of difference, scale of knowledge estimation, resentment, adequacy of evaluation, high level of awareness, choice justifications, demands, opinions, suggestions, and expectations. Later, the codes were sorted and clustered into themes, which were derived from the data and not predetermined. Three themes yielded out of this process. They are: views on CAT tools experience, opinions about CAT courses, and suggestions for future curriculum. The analysis entailed considering how each theme is related to the interview questions and how both help to answer the research questions (Magnusson \& Marecek, 2015).

Throughout the analysis, some correlations were found between some variables of the survey. The results were conveyed in a Pearson's correlation coefficient $(r)$. Correlations between variables do not mean that one variable causes the other, but they mean that the variables are related (Saldanha \& O'Brien, 2014). Also, the statistical significance of the correlations was reported and presented by (P-value).

\section{Results}

\section{The Study Plans of the Translator-Training Programs}

The translation programs in the five universities have almost similar strategies in teaching the CAT course, which are as follows: in-class discussions, guided practical training, lectures, inclass exercises and handouts, presentations, computer lab tutorials, etc. The assessment methods go in line with these strategies to achieve the desired learning outcomes, which include: quizzes, in-lab practice and participation, constant indirect assessment, translation projects, midterms, assignments, in lab collective activities, and final exams.

Even though the universities have different names for their translation programs and diverse curricula, their objectives are nearly the same. They aspire to prepare professional translators and interpreters, promote the aspect of scientific research, meet the market demands, and contribute to the translation industry by enriching the translation from and into the Arabic language. Also, they supply the market with certified translators.

Regarding the CAT courses, all of the universities provided one course in CAT tools, except IMSIU, which instead provided a course in CALL. As for the study plans, KSU and PNU had two plans, one was old and one was new. Also, IMSIU had two plans; however, one was current and one was new, which has not yet been implemented entirely to the curriculum. The lectures were divided differently in each program; some were more theoretical than practical, some were the opposite, and some were not clear. Even though the CAT courses introduced the students to more than one tool, SDL Trados was the main software program that the CAT courses in most of the universities focused on. Since other translation courses and graduation courses were analyzed, some of them comparatively integrated CAT tools. While some of these courses mentioned CAT tools as an option to be used by the students in the course. 
Table 1. The number of CAT courses provided by the universities

\begin{tabular}{|l|l|}
\hline Universities & Number of CAT Courses \\
\hline KSU & 1 \\
\hline IMSIU & 0 \\
\hline PNU & 1 \\
\hline PSU & 1 \\
\hline SEU & 1 \\
\hline
\end{tabular}

Furthermore, all of the courses aimed to achieve almost the same objectives. They had almost the same evaluation and improvement processes, regarding the courses, the students' achievement, and the teaching staff. In addition, all of them had similar requirements, except the course provided by PSU, which fulfilled all of the requirements. In regards to the material used in the courses, all of them used textbooks, some electronic material, and the course's software programs. On the other hand, the content of each course differed from one university to another, even from one plan to another of the same program, as the courses are updated periodically.

\section{Survey}

As stated above, an electronic survey was used to collect quantitative data. 340 translation students and graduates participated in the survey during a period of one month and a half. After excluding the 22 irrelevant responses, the number of participants became 318 . The analysis was accomplished using statistical methods, and the results are presented below in four separate sections. They are as follows:

\section{Respondents' profile}

This section addresses a categorization of the respondents into groups based on their gender, universities, year of graduation, computer skills competence, occupation, and the number of CAT courses they took in their universities. Since not all of the universities included in this study have a male section, the number of male participants was lower than the female participants. The male participants constituted only (8\%) while the female participants constituted (92\%) of the total participants. They are distributed as follows: 


\section{Participants' Distribution \\ Female $\square$ Male}

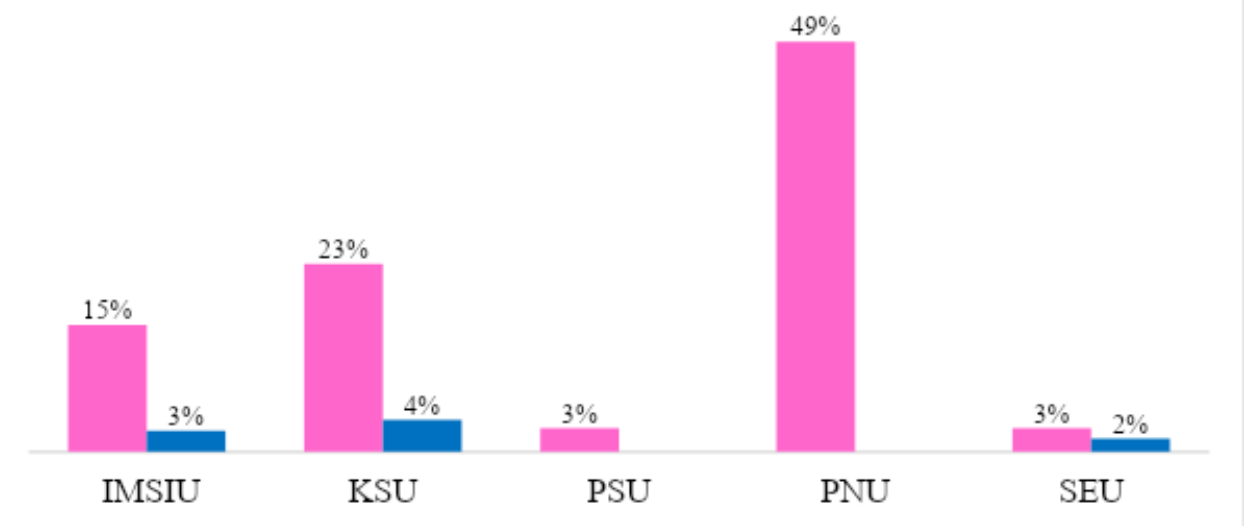

Figure 1. Distribution of the participants in their universities

In terms of the graduation year, almost half of the participants (45\%) were graduates, while more than half of them $(55 \%)$ were students. They are divided as follows:

Year of Graduation

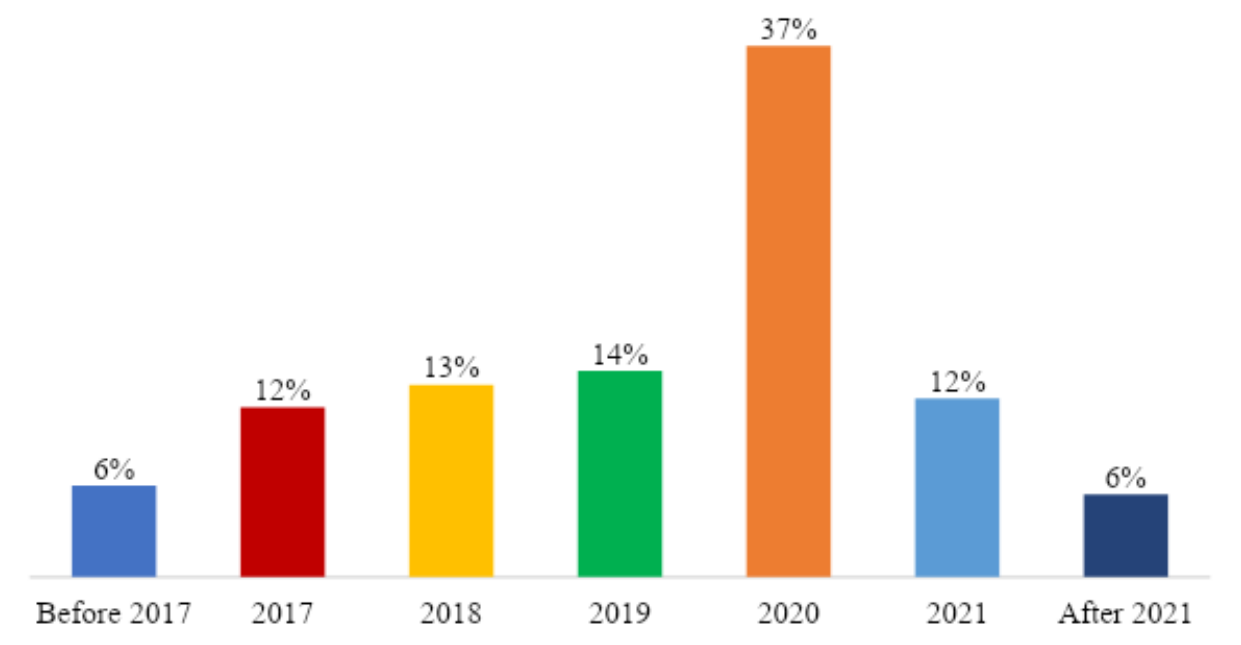

Figure 2. Participants' year of graduation and expected year of graduation

Then, the respondents were asked to rate their computer skills from excellent to poor. The majority (43\%) rated themselves as 'Good' users of the computer and (41\%) of them as 'Excellent' users. Whereas (14\%) presented an adequate level of computer skills, only (2\%) reported that their computer skills are poor. 


\section{Computer Skills}

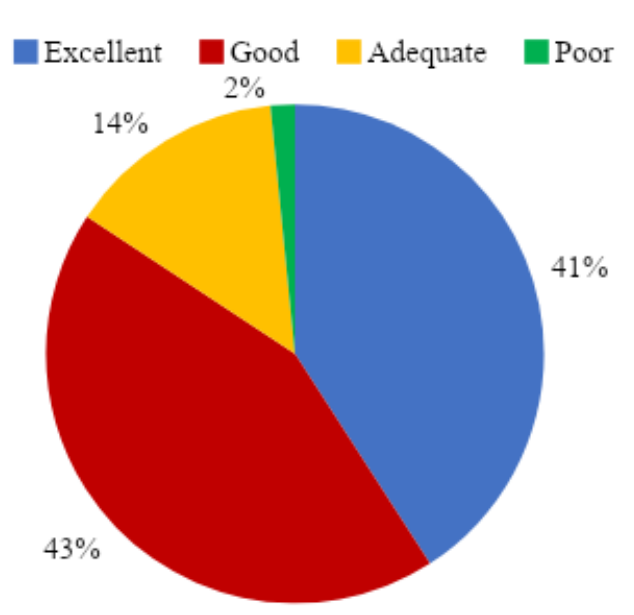

Figure 3. Participants' computer skills competence

Moreover, the occupation question was directed only to the graduate participants to discover whether the translation is their main or additional job. However, some of the student participants answered the question and showed some considerable results. The majority of the graduate respondents $(51 \%)$ work as translators, while (42\%) of them, translation was an additional occupation, and only (7\%) had other jobs. As for the students, more than half of them (56\%) work as part-time translators.

\section{Translation as an Occupation}

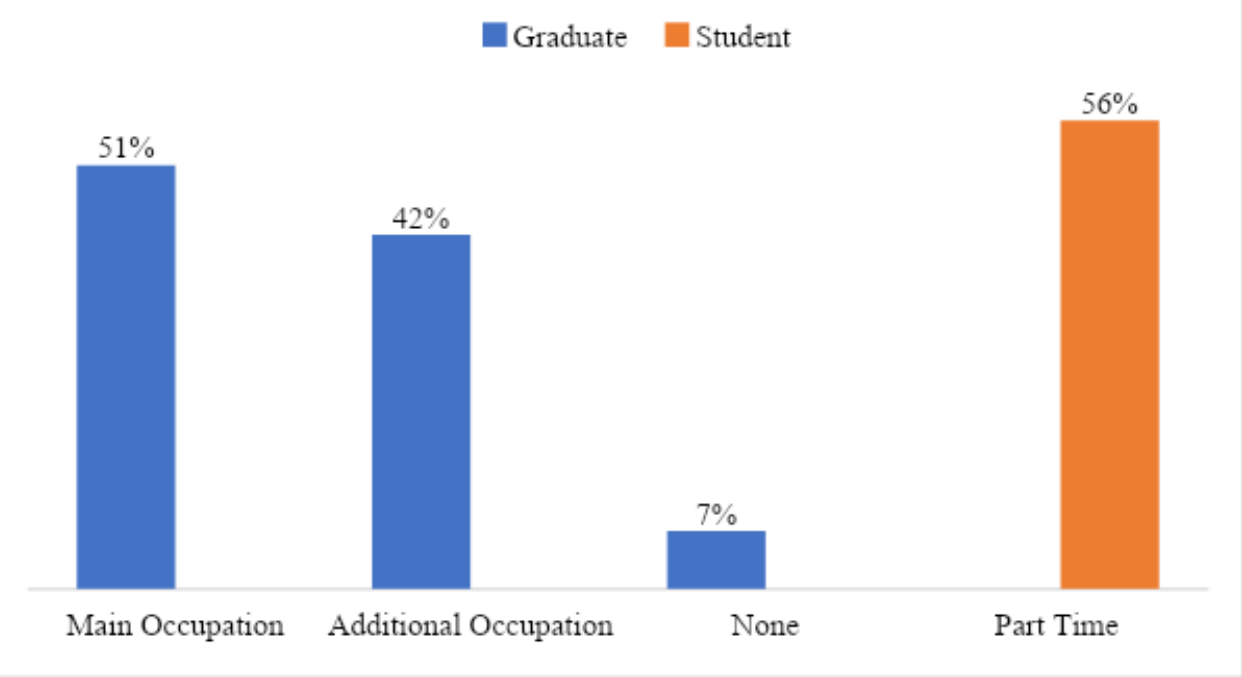

Figure 4. Participants' occupation

To delve deeper into the respondents' profile and the situation of CAT tools in their universities' translation program, the respondents were asked about the number of CAT courses they took in their universities. Most of the participants reported that they took only one course 
(49\%) in PNU, (23\%) in KSU, (4\%) in SEU, and (3\%) in PSU. By contrast, all IMSIU respondents $(18 \%)$ reported that no CAT courses were offered by their university. Similarly, a few participants from KSU (3\%) and SEU (1\%) did not have the chance to take the course in the university.

Number of CAT Courses Taken in the University

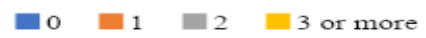

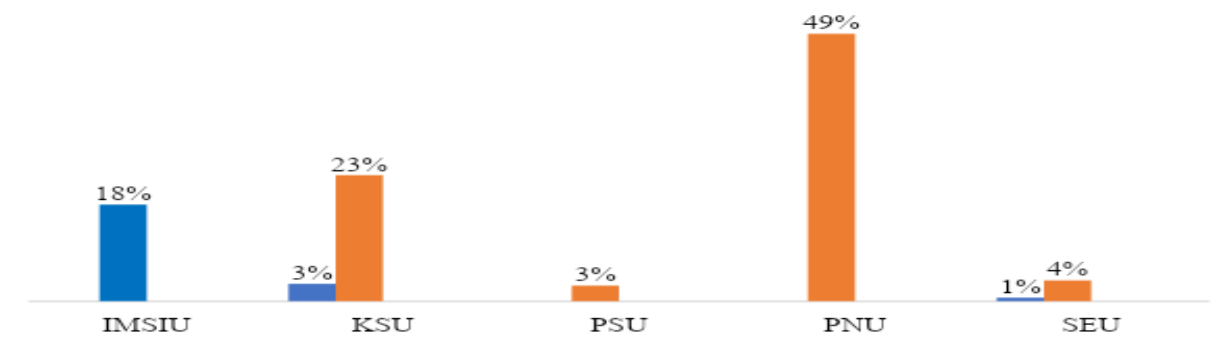

Figure 5. Number of CAT courses provided by the universities

\section{Familiarity with CAT tools}

This section revealed whether the participants were familiar with CAT tools or not and how they first became familiar with them. Familiarity here means having knowledge of the CAT tools and not practical experience. It asked them to rate their familiarity level and source (university courses, online courses, training workshops inside or outside the university, or other sources). A significant percentage of the participants (65\%) reported that they were 'to some extent familiar' with CAT tools, $(22 \%)$ of them rated themselves as 'very familiar,' while $(12 \%)$ of the participants were not familiar with these tools.

As for the sources of their familiarity, university courses were the primary source for $(51 \%)$ of participants to be 'to some extent familiar' with CAT tools and (16\%) of them to be 'very familiar.' While (8\%) turned into 'to some extent familiar' and (1\%) into 'very familiar' from online courses. Training workshops outside the university helped $(3 \%)$ of the participants to be 'very familiar' with CAT tools and $(2 \%)$ to be 'to some extent familiar." Similarly, $(3 \%)$ of the respondents became approximately familiar with CAT tools from the workshops inside the university, and (1\%) became "very familiar." Whereas (1\%) became very and relatively familiar with such tools from other sources.

Familiarity With CAT Tools

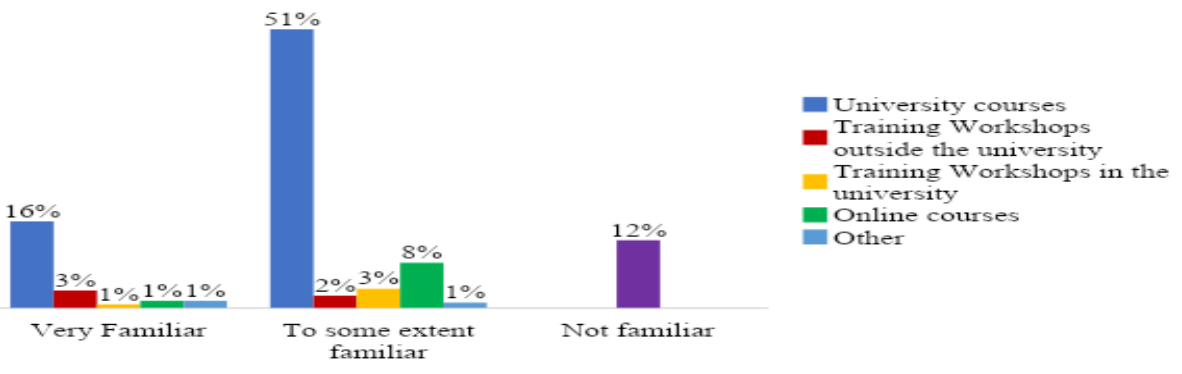

Figure 6. Participants' level \& source of familiarity with CAT tools

Arab World English Journal for Translation \& Literary Studies 


\section{Usage of CAT tools}

This construct investigated the participants' usage of CAT tools in their translation tasks and the extent to which they use them. Almost half of them (45\%) do not use CAT tools in their translation tasks. As for the ones who use them, (12\%) confirmed to use them frequently, (9\%) occasionally, and only (2\%) rarely. While the informants who partially use CAT tools, $(26 \%)$ of them use these tools from time to time, $(5 \%)$ use them frequently, and (2\%) use them, but rarely.

Usage of CAT Tools in Translation Tasks

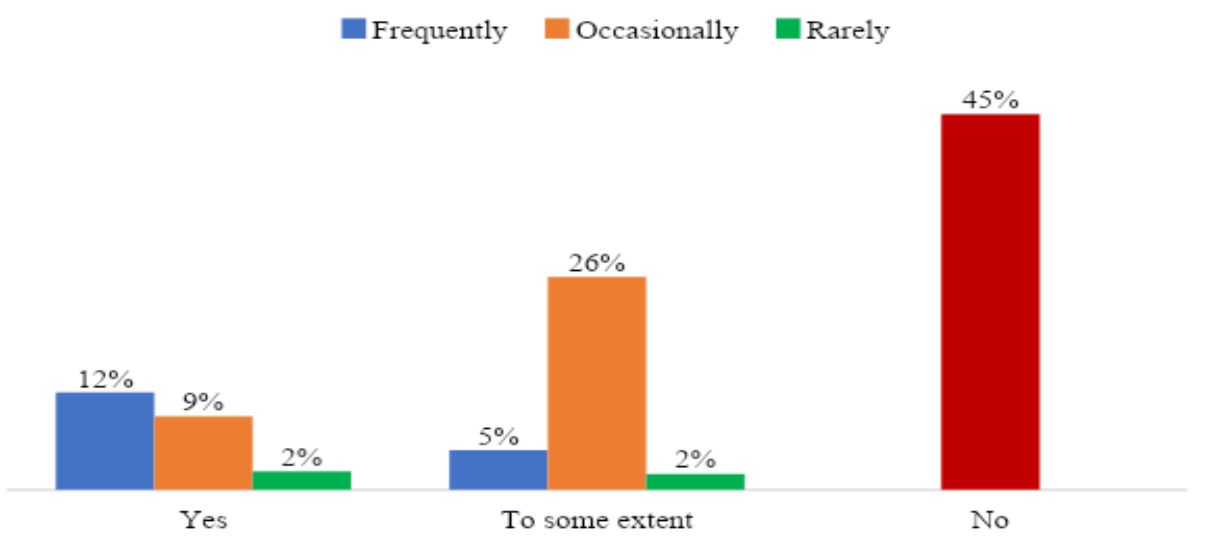

Figure 7. Participant' usage of CAT tools in translation tasks \& the extent of their usage

\section{CAT courses in the universities and the participants' opinions}

This section revolved around the state of CAT courses in the universities under study and the participants' opinions about them. It asked the participants if the instructors of other translation courses encouraged them to use CAT tools in their courses or not. Also, it investigated the state of the CAT and technology-related workshops provided by the universities and the CAT labs' infrastructure.

Regarding the utilization of CAT tools in other translation courses, more than half of the participants $(58 \%)$ stated that they did not use them across translation courses but only in CAT courses. However, (19\%) used them in some other translation courses, and only (3\%) used CAT tools across all the translation courses. In contrast, $(20 \%)$ of the participants had never used CAT tools.

Usage of CAT Tools Across Translation Courses
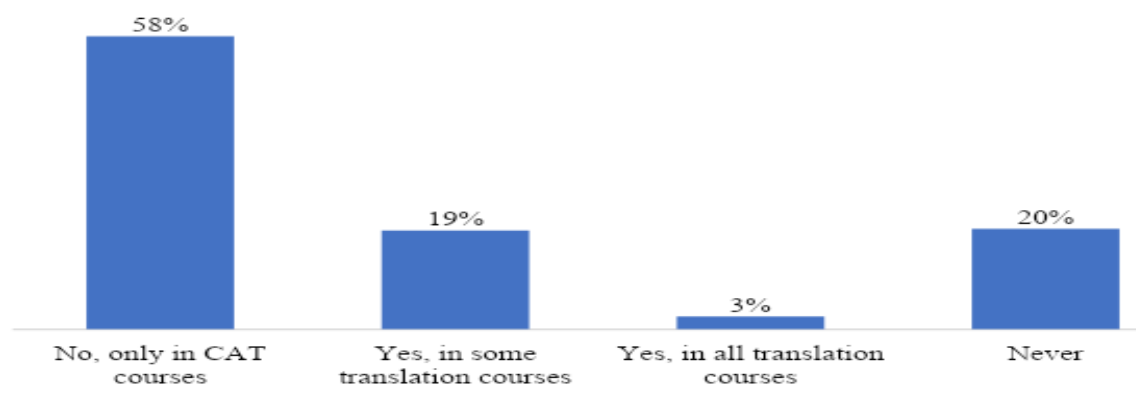

Figure 8. Participants' usage of CAT tools in other translation courses

Arab World English Journal for Translation \& Literary Studies 
Then, the participants were asked whether their instructors of other translation courses encouraged them to use CAT tools in their courses. More than half of the participants (55\%) were not encouraged to use CAT tools across translation courses. However, $(27 \%)$ of them were "to some extent" encouraged, and (19\%) their instructors of other translation courses encouraged them to use CAT tools in the courses they teach. They are detailed below:

Instructors' Encouragement of CAT Tools Usage Across Translation Courses

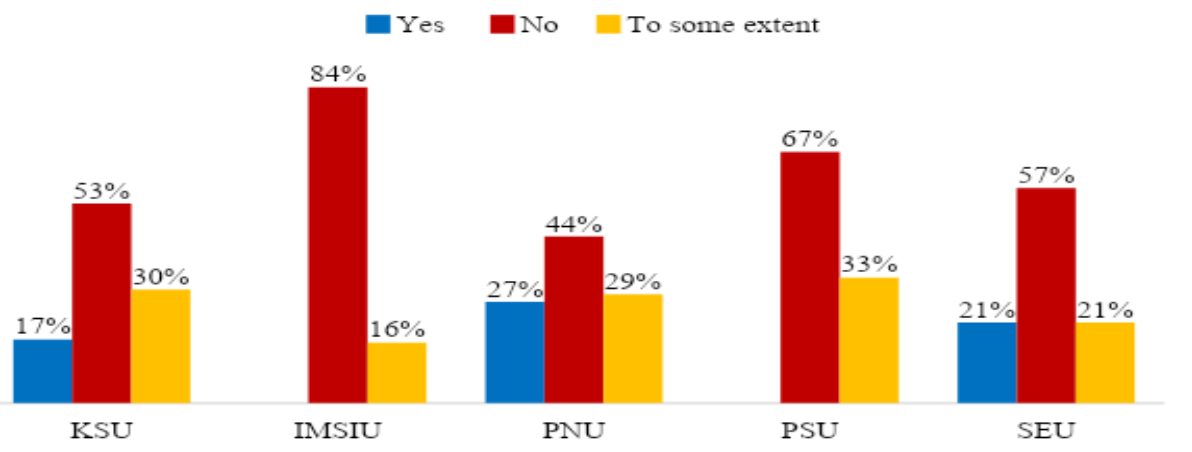

Figure 9. The translation instructors' encouragement of the usage of CAT tools across translation courses

The survey also investigated the role of the translation departments regarding the CAT related workshops they provided to the translation students. Most of the respondents (46\%) indicated that the university did not provide them with workshops related to CAT tools. On the other hand, $(27 \%)$ reported being provided with workshops by the university, and $(27 \%)$ indicated that they were "to some extent" provided with workshops. More details are provided below:

\section{CAT Tools Workshops Provided by the Universities}

Y Yes $\square$ No $\quad$ To some extent

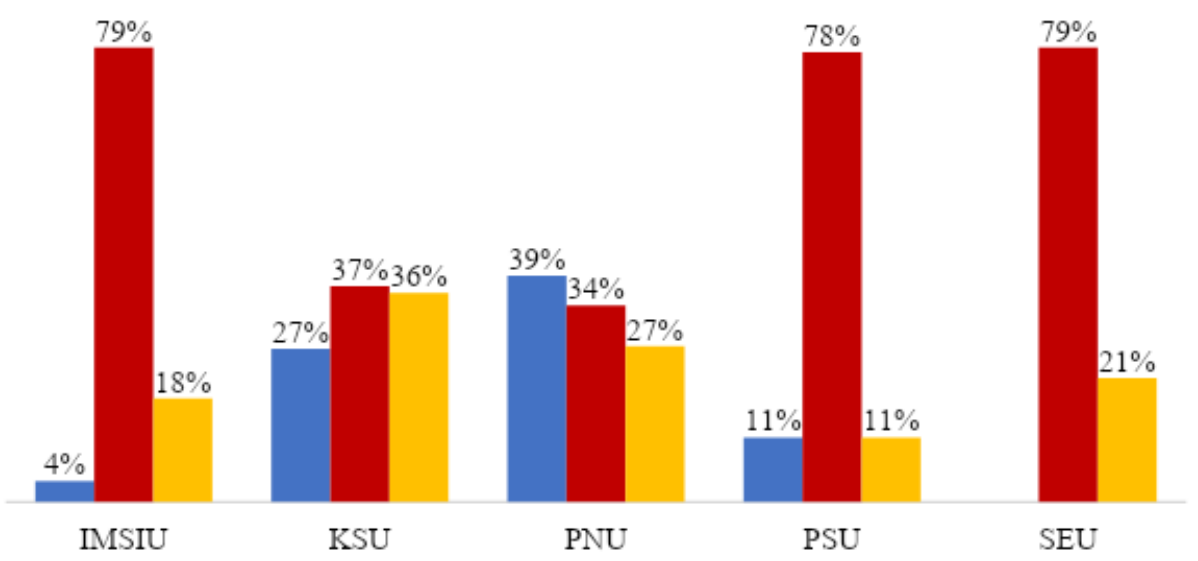

Figure 10. CAT-related workshops provided by the universities

Afterward, the universities' labs were explored in terms of being equipped with the software programs covered in the course and other necessary items. As their university offers a 
CALL course, IMSIU's participants were able to evaluate the labs in their university. More than half of the participants (59\%) reported that the labs were not equipped with the necessary items; however, $(20 \%)$ considered them partially equipped, and (20\%) the labs were fully equipped for them. More details are presented as follows:

Universities' Labs Equipment

$$
\text { - Yes No } \square \text { To some extent }
$$

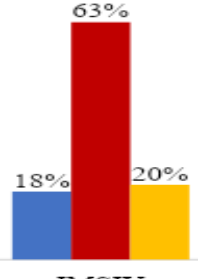

IMSIU

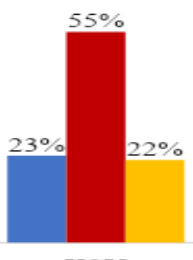

KSU

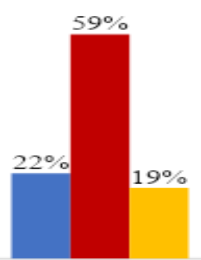

PNU

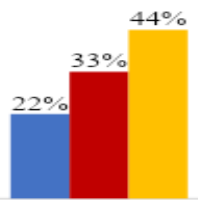

PSU

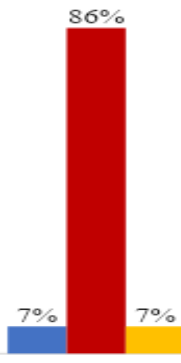

SEU

Figure 11. The infrastructure of CAT labs in the universities under study

\section{Correlations between variables}

Throughout the analysis, some correlations between the variables were spotted. The instructors' encouragement to use CAT tools across translation courses was correlated with the participants' usage of CAT tools in other translation courses, and the result was $(1.0, p=0.006)$.

Table 2. Pearson's correlation coefficient

\begin{tabular}{|l|c|c|c|}
\hline Variables & $\begin{array}{l}\text { Correlation } \\
\text { coefficient }(r)\end{array}$ & P value $(p)$ & $\begin{array}{l}\text { Significance } \\
\text { level }\end{array}$ \\
\hline $\begin{array}{l}\text { Instructors' } \\
\text { encouragement }> \\
\begin{array}{l}\text { Usage of CAT tools } \\
\text { across courses }\end{array}\end{array}$ & 1.0 & 0.006 & \\
\hline
\end{tabular}

***. Correlation is significant at the 0.01 level (2-tailed).

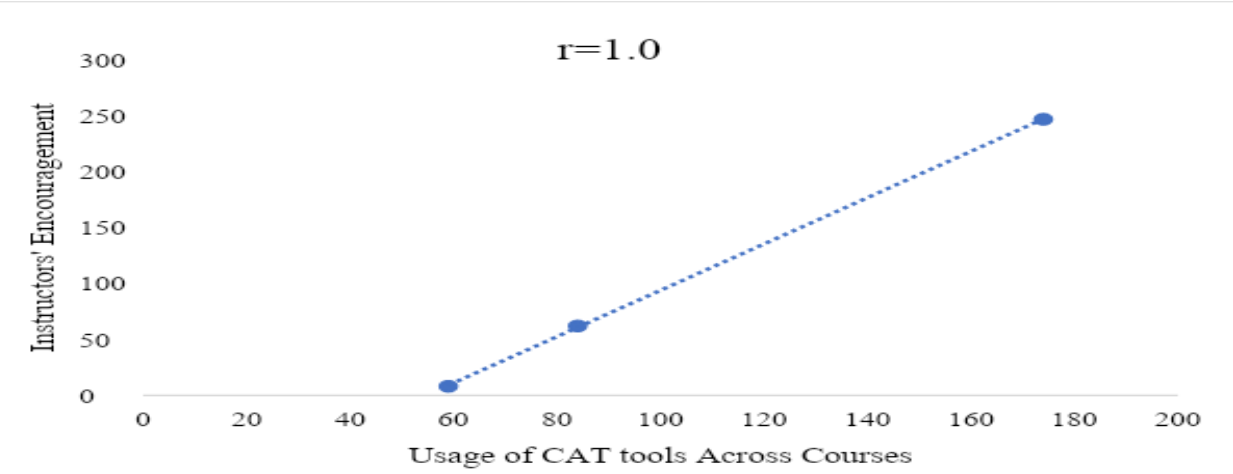

Figure 12. Correlation between the participants' usage of CAT tools across translation courses \& their instructors' encouragement 


\section{Semi-structured Interview}

The interviewees' responses were based on their experiences with CAT tools. Since the interviews were analyzed using the content analysis method, three themes emerged throughout the analysis. They are: views on the CAT tools, opinions about CAT courses, and suggestions for future curriculum. They are summarized below:

\section{Views on the CAT tools experience}

This theme addressed the questions that revolved around the interviewees' experience with CAT tools, which reflected both the situation of CAT tools in their universities and their usage of such tools either in the translation courses or translation tasks. When the participants were asked about their general experience with CAT tools, they highlighted the challenges and limitations, and developed some sort of disappointment toward the course they took in the university, mainly in terms of the course's practicality. Then, they talked about their general experience with CAT tools. Below are some of their responses that were extracted from the interview transcript:

- I knew about CAT tools from the internet and I liked their concept in translation. Unfortunately, our university does not provide a CAT course in its curriculum.

- First of all, my experience as a BA student taking CAT tools was very limited. The programs that I was introduced to were very important in the field of translation, however, the scope of the practice was very limited... As for the rest of the programs, personally as a graduate, I can only remember Trados the other programs I remember them being useful but they didn't stick with me throughout my professional life.

Then, they developed some sort of resentment regarding the availability of the licenses and mentioned some differences between the male and female section in providing such licenses.

- No, we used the trail.

- No, not even a trial. The situation in the male section differs from the female section. Also, it depends on the coordinator of the course, some of them feel responsible for their students and make sure that they obtain the license and some are not.

After that, they showed some differences in their experience with their CAT instructors, regarding their scale of knowledge of the course material and technology.

- No, she was not informed of the course. She used to skip a lot of things.

- Yes, very qualified.

Opinions about CAT courses

This theme shed some light on the interviewees' opinions about CAT tools in particular situations. The interviewees' answers had a high degree of similarity in almost all the questions. They developed a negative attitude toward the course in terms of its adequacy to prepare them for the workplace. Some of their responses are presented below:

- No, the course was not enough.

- No, because the features that we were introduced to were very limited, so they were not enough to take you to a very technical place, where you can confidently use technology to aid your translation.

Arab World English Journal for Translation \& Literary Studies 
Then, they showed a high level of awareness of the CAT tools' importance in the job market. Most of them chose the translator with CAT tools experience, and they justified their choices when they were asked about which translator will get more opportunities in the job market.

- The one with definitely, because everything is integrated with technology nowadays.

- The one with, because he will do more work with CAT tools, because they help speeding up the translation and increasing the productivity of the translator.

Afterward, they showed some demands in their suggestions when they were asked about the effective ways of motivating them as translation students to use CAT tools. They focused mainly on three main aspects, which were: availability of the licenses, the role of the teaching staff, and more practical exposure to the tools.

- Give us unlimited access, by providing licenses for us. Also, the instructors play a key role in this regard.

- The best way to encourage us as students is by providing licenses for us so we can use them for the entire year not just for one month. Also, if all the translation courses and the graduation project were submitted through CAT tools, in this way I would investigate the program more and learn more about it, and then when I go to the workplace, I already know how to use them and I would be confident of my abilities.

\section{Suggestions for future curriculum}

This theme gave the interviewees the freedom to provide elaborative suggestions regarding their universities' translation curriculum, whether enlightening ideas, workshops, or courses that they wanted to be added to the curriculum. The interviewees' answers yielded several suggestions. However, most of their suggestions focused on three areas; in particular, they were: more technology involvement and more integration of CAT courses, more preparation for them to enter the job market, and more maintenance and equipment for the labs. They are as follows:

- The basic English courses should be less and translation courses should be more, individual feedback in the translation courses, more translation practice not just theories to prepare the students for the job market.

- The curriculum was dense and tough for BA translation students and there were no labs. So, I would suggest a rearrangement of the curriculum with more technology courses and maintenance of the labs.

\section{Discussion}

The present study utilized a mixed-methods approach to investigate the state of CAT tools integration into the translator-training programs of some universities in Saudi Arabia and the extent of the students/graduates' usage of such tools in different translation tasks and courses. Therefore, data were collected from diverse sources (the study plans of the translation programs, the electronic survey, and the semi-structured interview) and analyzed using different methods (content analysis method and statistical methods). The results yielded from the analysis are discussed, and correlations and contradictions are made to drive to new conclusions, which contribute to providing statistical data on the state and usage of CAT tools in some universities in Saudi Arabia. The information is important, as the study discusses a topic that has been notably reflected on in the previous studies, but rarely investigated. Therefore, it allows the decision-makers, curriculum developers, universities, translation departments, and teachers to consider the significance of 
technology in general and CAT tools in particular to the future of the translation students and graduates. Also, how these tools begin to assume an important place in the translation market.

As mentioned before, not all of the universities included in this study have a male section therefore, the female participants $(92 \%)$ outnumber the male participants $(8 \%)$. As for their computer skills competence, the results show that the majority of the participants have Good (43\%) to Excellent (41\%) computer skills, which means that they are technically skilled and aware of the technology. Also, a great percentage of the graduates $(51 \%)$ work as translators or have the translation as an additional job (42\%). While more than half of the students $(56 \%)$ work as parttime translators. This indicates that they have some practical experience in the job market, whether short or average.

Regarding their familiarity with CAT tools, the respondents show a high level of familiarity as $(22 \%)$ are very familiar, and $(65 \%)$ are to some extent familiar. Only (12\%) are not familiar, which can be due to the year of graduation as some of the participants graduated before 2017 (6\%) and did not have the chance to take CAT courses. Besides, some of them will graduate after 2021(6\%) and have not taken the course yet. This reveals that the developments of the translation programs and the addition of the CAT courses in the curricula make the students and graduates of later years more familiar with CAT tools and have a more positive attitude toward technology in translation, which was reflected in their responses throughout the interview. Similar findings were reached by (Alotaibi, 2014) when the students showed a more positive attitude toward CAT software at the end of the CAT course when they became familiar with the tools and their potential benefits and drawbacks.

As for the state of CAT tools integration into the investigated universities' translation programs, which is one of the main objectives of the current study. It can be said that CAT tools are not integrated effectively into the translator-training programs, as the study plans indicate that not all of the universities provide CAT courses in their translation programs. This is also confirmed by the participants of some universities in the survey (18\%). In addition, those participants show their disappointment in the interview that their university does not offer the course. Meanwhile, the universities that provide CAT courses lack some elements that hinder the efficacy of integrating these tools into their translation programs. Their study plans show that all of them provide only one CAT core course, and the majority of the survey participants (79\%) indicated that as well. The number of the CAT courses was among the main aspects that the participants show their resentment about, as they state in the interview that one course is not enough for them to practice and explore the tools. Also, it was not enough to prepare them for the job market, and they suggest more integration of CAT courses in the translation curriculum. This goes in line with Kiraly's (2014) statement about the inadequacy of providing one course to enable the students to acquire the technical competence required in a professional workplace.

Moreover, the workshops provided by the universities on CAT-related topics and the infrastructure of the labs can be additional indicators of the state of CAT tools integration. Most of the universities rarely provide workshops on such topics, and the majority of the participants proved that; for more details (see Figure 10). This suggests a lack of disseminating knowledge 
about CAT tools among the students since only (4\%) of the participants first became familiar with CAT tools through the universities' workshops.

Whereas, the infrastructure of the labs in almost all of the universities seems to be not fulfilling the course requirements, as they are reported to be not equipped by nearly all of the participants in terms of the availability of the necessary items such as enough computers, the installation of the course's software, internet, etc. (see Figure 11). They repeatedly suggested more enhancement and equipment for them in the interview. Therefore, it could be inferred that both the CAT-related workshops and the infrastructure of the universities' labs indicate a lack of CAT tools integration and a need for providing the students with more technology and an environment that supports the use of technology in translation. This is in line with Fatani's (2007) claims that providing the students with more technology and more IT maintenance will enhance the translatortraining programs, which will reflect on their outcomes.

The study also aims to investigate the translation students/ graduates' usage of CAT tools in different translation tasks and courses. Despite their familiarity with CAT tools, excellent computer skills, and their experience as translators or part-time translators, the results reveal that most of the participants do not use CAT tools in their translation tasks (45\%). Also, more than half of the respondents (58\%) report not using CAT tools in other translation courses; instead, the usage of these tools is limited to the CAT core courses. The lack of CAT tools usage across translation courses was also confirmed by (Al-Jarf, 2017; Alotaibi, 2014; Mohammed, 2020) as they suggest more integration and practice of such tools.

The participants are prepared to be professional translators, and not using CAT tools contradicts the findings of (Lagoudaki, 2006), as the majority of the participants in her study, who are professional translators, report using more than one tool. As well, this can affect the participants' performance in the workplace, which may justify both Samson's (2005) statement and Fatani's (2009) indication. As the former stated that some companies are bitterly disappointed about the performance of the translation graduates with CAT tools. While the latter attributed the negligence of the governmental institutions, organizations, and other corporations of the translation industry in Saudi Arabia to the lack of qualified translators in the market at various levels, along with the technical level.

The lack of usage can be derived from many factors; one of them is the absence of the instructors' motivation. Many studies (Alotaibi, 2014; Bowker \& Marshman, 2009; Elshafei, 2014; Yao, 2017) have mentioned the critical role of the instructors in motivating the students and facilitating the learning process. In this regard, the results show a strong positive correlation between the students' usage of CAT tools across translation courses and the instructors' encouragement ( $r=1.0, p=0.006)$. This indicates that the less the instructors' motivation, the lack of CAT tools usage across courses. Also, the participants emphasize in the interview that their instructors do not motivate them to use CAT tools either in other translation courses or in the graduation project, which contradicts some course specifications that stated that the students are encouraged to use CAT tools in other translation courses and the translation project.

Arab World English Journal for Translation \& Literary Studies 
The unfamiliarity of the instructors of other translation courses with CAT tools can be the reason behind not motivating the students to use them in their courses. The findings of (Yao, 2017) revealed that the majority of the translation instructors indicated to be not very familiar with CAT tools, which affected their integration in teaching translation. Even though the CAT instructors in this study are evaluated to be technically qualified by most of the participants in the interview, they seem to be not disseminating the importance of CAT tools among their colleagues, which led to the lack of encouragement.

The results reveal that the usage of CAT tools by the majority of the participants $(58 \%)$ was restricted to the CAT core courses. This implies the lack of Knowledge Sharing, which was explored by (Ghabban et al., 2018) to enhance the communication between the academic staff in some Saudi universities. The instructors responsible for the CAT courses in the universities under study seem to be not sharing the importance of these tools for the students' future career with their fellow instructors of other translation courses, which made the latter less supportive of using CAT tools in their courses. Nevertheless, exchanging experiences and sharing knowledge between the teaching staff may not be activated not because of their unwillingness to share, but it may be due to the absence of the concept of $\mathrm{KS}$, which could be related to the nature of knowledge or any other factor that affects its practice.

What is more, the design of the course could be one of the factors of the participants' lack of practice of CAT tools. The results of the course specifications point out some sort of unclarity of the CAT lectures' structure, as some were more theoretical than practical, some were the opposite, and some were not clear. Also, the participants indicated in the interview that the course was limited and not enough to prepare them for the job market. The relationship between the course design and the students' experience was highlighted by (Elshafei, 2014), as she drew a correlation between the weakness of students' translation and the lack of well- designed translation courses. All of which can affect the preparation of the students and graduates for the marketplace and widen the gap between the translator-training programs and the translation market. This goes in line with Abu-ghararah's (2017) claims, since she asserted a huge gap between the academic training and the needs of the translation market in Saudi Arabia.

Furthermore, the software's licenses can be a potential factor of the limited usage of CAT tools. Nearly all of the respondents use the trial version, which lasts only 30 days. Besides, some of them mentioned some differences between the sections (male and female) in terms of providing the licenses. This can be due to the lack of funds, which correlates with (Alotaibi, 2014; Yao, 2017), where both stressed the lack of the university's funds and how it affected the students' experience with CAT tools. Although the participants are introduced to more than one software during the course, the main focus is on SDL Trados. This program is not cloud-based; therefore, it needs to be installed on the computer. Using the trial version affected the participants' experience, as they adversely stressed that in the interview. They were limited to a specific time, which prevented them from exploring the program.

On the other hand, the results show the participants' awareness of the importance of CAT tools for them as translators. In the interview, most of them consider having CAT experience as a factor that can increase their opportunities in the job market. Similarly, they strongly reflect on 
more integration and positively suggest it in their responses to more than one question in the interview. This can be correlated with Abu Dayyeh's (2020) findings, when the majority of the translators and translation students reported the necessity of integrating more CAT tools in the translation curriculum of their universities.

\section{Conclusion}

With the widespread use of technology and the increasing demand of the translation market for technically qualified translators, the education industry tried to cope with these demands. Therefore, plenty of universities around the world, including Saudi universities developed their translator-training programs and integrated some technological tools to prepare their translators to be for the job market. Also, many scholarly works have been done in an attempt to investigate the integration of technology in general and these tools in particular into the translation programs, yet little was conducted on Saudi universities.

To bridge that gap, the current study investigates the state of CAT tools in both sections (male and female) in five Saudi universities, which are IMSIU, KSU, PNU, PSU, and SEU. Also, the usage of these tools by their translation students/graduates in various translation tasks and courses. The findings prove that the state of CAT tools integration in the universities is still in its initial stages and needs more consideration, as not all of the universities provide CAT courses in their translation programs. While the ones that offer them, do not effectively integrate CAT tools into their translation programs. They only offer one CAT course, which was indicated to be not enough by the participants to practice these tools and be prepared for the professional settings.

In addition, the present study reveals a lack of CAT tools usage by the translation students and graduates in the translation tasks and across translation courses. It is attributed to many factors, such as the absence of the instructors' motivation, the lack of sharing knowledge with the teaching staff of other translation courses, and the lack of practice of these tools. Also, the CAT software licenses and the design of the translation courses were among the potential factors that hindered the usage of these tools. Furthermore, the participants' awareness of the benefits of CAT tools for them and their future career was revealed, since most of them positively supported more integration of courses related to CAT tools and technology. As well as, they highly suggested more integration of CAT tools across translation courses.

These tools have been a topic of interest for a myriad of researchers and their insights proved that the translators are the main factor of the success of the translation process. Also, such tools were not meant to replace human translators at all, but to aid them, since they are in charge of the translation, even with technology. Regardless of the negative effects of these tools that may run across the border, the rapid technological changes in the translation industry and the demand of the translation market for professional translators with excellent technical skills make CAT tools integration into the translation programs more important than ever before.

The current study poses some suggestions to be followed in future research. The state of CAT tools was investigated in an academic context in a particular city in Saudi Arabia, which cannot be generalized to other contexts. Thus, it is recommended that this investigation be carried 
AWEJ for Translation \& Literary Studies Volume, 5 Number 1. February 2021

The Integration of Computer-Aided Translation Tools

Al-Rumaih

out in other universities in Saudi Arabia or around the world, because of the importance of such tools for the translation students and graduates.

\section{About the Author}

Lama A. Al-Rumaih is an English/ Arabic translator. She translated a great number of articles and texts in different fields and some of her translations are published. She has a Master's degree from Princess Nourah University in the field of Specialized Translation. She is a member of some platforms in social media that aim to enrich the Arabic content through translation, such as Ollemna. Her research interests include translation studies, translation technology, post-editing, and audio-visual translation.ORCiD: https://orcid.org/0000-0003-3506-2757

\section{References}

Abu Dayyeh, I. (2020). Use and Evaluation of Computer-Aided Translation Tools (CAT) on the Word Level from the Perspective of Palestinian Translators and Translation Trainees. Arab World English Journal For Translation and Literary Studies, 4(1), 111-130. https://doi.org/10.24093/awejtls/vol4no1.9

Abu-ghararah, B. A. (2017). The Gap between Translator Training and the Translation Industry in Saudi Arabia. Arab World English Journal For Translation and Literary Studies, 1(4), 107-118. https://doi.org/10.24093/awejtls/vol1no4.8

Al-Jarf, R. (2017). Technology Integration in Translator Training in Saudi Arabia. International Journal of Research in Engineering and Social Sciences, 7(3), 1-7.

Alotaibi, H. M. (2014). Teaching CAT Tools to Translation Students: an Examination of Their Expectations and Attitudes. AWEJ. Special Issue on Translation, 3, 65-74. www.awej.org

Alshrief, S. (2019). First-generation College Students in Saudi Universities. Unpublished manuscript.

Bowker, L. (2002). Computer-Aided Translation Technology: A practical introduction. Canada: University of Ottawa Press. https://doi.org/10.1017/CBO9781107415324.004

Bowker, L. (2015). Computer-Aided Translation: Translator Training. In C. Sin-wai (Ed.), Routledge encyclopedia of translation technology (pp. 88-104). London: Routledge.

Bowker, L. (2019). Fit-for-Purpose Translation. In M. O’Hagan (Ed.), The Routledge Handbook of translation and technology (pp. 453-468). London: Routledge. Forthcoming.

Bowker, L., \& Marshman, E. (2009). Better Integration for Better Preparation: Bringing Terminology and Technology more Fully into Translator Training Using the CERTT Approach. Terminology, 15(1), 60-87. https://doi.org/10.1075/term.15.1.04bow

Bowker, L. (2020). Translation Technology and Ethics. In K. Koskinen \& N. Pokorn

(Eds.), The Routledge Handbook of Translation and Ethics (pp. 262- 278). Oxon, NY: Routledge.

Creswell, J. W., \& Clark, V. L. (2017). Designing and Conducting Mixed Methods Research (3 ${ }^{\text {rd }}$ ed). Los Angeles: SAGE Publications.

Dornyei, Z. (2007). Research Methods in Applied Linguistics: Quantitative, Qualitative, and Mixed Methodologies, Oxford: Oxford University Press.

EAMT - European Association for Machine Translation. (n.d.). Retrieved from 
AWEJ for Translation \& Literary Studies Volume, 5 Number 1. February 2021

The Integration of Computer-Aided Translation Tools

Al-Rumaih

http://www.eamt.org/mt.php

Elshafei, N. (2014). Implementing Professional Approach Within a Translation Course to Sharpen the Student/Translator's Practical Skills for Demands of the Labor Market.

International Journal of Applied Linguistics and English Literature, 3(2), 145-154. https://doi.org/10.7575/aiac.ijalel.v.3n.2p.145

Fatani, A. (2007). Globalization and the Translation Industry in Saudi Arabia: Factors Inhibiting the Use and Integration of Translation Technology into Mainstream Coursework. UNESCO Forum on Higher Education: 2nd Regional Seminar for Arab States.

https://studylib.net/doc/7805903/globalization-and-the-translation-industry-in-saudi-arabia

Fatani, A. H. (2009). The State of the Translation Industry in Saudi Arabia. Translation Journal, 13(4), 1-8. https://translationjournal.net/journal/50saudi.htm

Foddy, W. (1994). Constructing Questions for Interviews and Questionnaires: Theory and Practice in Social Research. Cambridge: Cambridge University Press.

Ghabban, F., Selamat, A., \& Ibrahim, R. (2018). New Model for Encouraging Academic Staff in Saudi Universities to Use IT for Knowledge Sharing to Improve Scholarly Publication Performance. Technology in Society, 55, 92-99. https://doi.org/10.1016/j.techsoc.2018.07.001

Harabi, N. (2009). Economic Performance of the Arabic Book Translation Industry in Arab Countries. Journal of North African Studies, 14(2), 203-219. https://doi.org/10.1080/13629380802343673

Kenny, D. (1999). CAT Tools in an Academic Environment: What Are They Good For? Target: International Journal of Translation Studies, 11(1), 65-82. https://doi.org/10.1075/target.11.1.04ken

Kiraly, D. (2014). A Social Constructivist Approach to Translator Education: Empowerment from Theory to Practice. Oxon, NY: Routledge.

Krüger, R. (2016). Contextualising Computer-Assisted Translation Tools and Modelling Their Usability. Trans-Kom - Journal of Translation and Technical Communication Research, 9(1), 114-148

Lagoudaki, E. (2006). Translation Memories Survey 2006: Users' Perceptions around TM Use. Translating \& the Computer, 28, 1-29

Magnusson, E., \& Marecek, J. (2015). Doing Interview-Based Qualitative Research: A Learner's Guide. Cambridge: Cambridge University Press. https://doi.org/10.1017/CBO9781107449893

McBride, C. (2009). Translation Memory Systems: An Analysis of Translators' Attitudes and Opinions, (Unpublished Master's Dissertation). University of Ottawa, Canada. http://hdl.handle.net/10393/28404

Mohammed, T. A. S. (2020). Investigating the Translation Programme at two Yemeni Universities in the Light of PACTE's Translation Competence Model. Al-Ustath Journal for Human and Social Sciences, 59(1), 103-121.

Pym, A. (2011). What Technology Does to Translating. The International Journal of Translation \& Interpreting Research, 3(1), 1-9. https://doi.org/10.12807/t\&i.v3i1.121

Pym, A. (2013). Translation Skill-Sets in a Machine-Translation Age. Meta, 58(3), 487-503. https://doi.org/10.7202/1025047a

Saldanha, G., \& O’Brien, S. (2014). Research Methodologies in Translation Studies. Oxon, NY:

Arab World English Journal for Translation \& Literary Studies 
Routledge.

Samson, R. (2005). Computer Assisted Translation. In M. Tennent (Ed.), Training for the New Millennium: Pedagogies for Translation and Interpreting (pp. 101-126). Amsterdam: John Benjamins Publishing Company

Seliger, W. H., \& Shohamy, E. (1989). Second Language Research Methods. Oxford: Oxford University Press.

Sin-wai, C. (2010). A New Curriculum for the Teaching of Translation Technology: The Teaching of a Translation Project Course as a Case Study. Journal of Translation Studies, 13(1-2), 83-154.

Sin-wai, C. (2013). Approaching Localization. In C. Millán \& F. Bartrina (Eds.), The Routledge Handbook of Translation Studies (pp. 347-362). Oxon, NY: Routledge.

https://doi.org/10.4324/9780203102893.ch25

Sin-wai, C. (2015). The Routledge Encyclopedia of Translation Technology. London: Routledge. Taylor, H. (2000). Does Internet Research Work? Comparing Online Survey Results with Telephone Survey. International Journal of Market Research, 42(1), 51-63.

Yao, S. (2017). Application of Computer-Aided Translation in English Teaching. International Journal of Emerging Technologies in Learning, 12(8), 105-117. https://doi.org/10.3991/ijet.v12.i08.7145 